\title{
GESTÃO DOS MÚLTTPLOS VÍNCULOS CONTRATUAIS NAS GRANDES EMPRESAS BRASILEIRAS
}

RESUMO

Este artigo analisa como os executivos das maiores empresas brasileiras estão lidando com a força de trabalho flexível, ao comparar a evolução do tratamento conferido aos trabalhadores do quadro efetivo das empresas com o tratamento conferido aos terceirizados. A pesquisa quantitativa realizada com 513 presidentes, diretores e al tos executivos de 179 empresas sugere uma evolução das práticas de gestão de pessoas em geral e um aumento da distância no tratamento conferido aos terceirizados em relação aos empregados, em aspectos fundamentais da gestão de pessoas, como recompensa monetária por metas atingidas, comprometimento com os resultados, autonomia e compartilhamento do aprendizado. Também há evidências da tendência de ampliação da contratação de terceirizados. Conclui-se que as maiores empresas brasileiras se encontram ainda despreparadas para lidar com a complexidade advinda da proliferação da contratação de profissionais com múltiplos tipos de vínculos contratuais.

\section{Maria Elizabeth Rezende Fernandes \\ UFMG-CEPEAD e Fundação Dom Cabral}

\section{Antônio Moreira de Carvalho Neto}

PUC-Minas e Fundação Dom Cabral

\begin{abstract}
The article analyzes how executives of the biggest Brazilian companies have been dealing with the flexible workforce, comparing the management of core personnel versus outsourced personnel. The quantitative research done with 513 presidents, directors and top executives of 179 companies shows an evolution in people management practices in general, although there has been a widening gap in the treatment outsourced workers receive. This gap can be observed in relevant aspects such as financial rewards for goals achieved, commitment to results, autonomy and sharing of learning experiences. While this research shows a growing tendency towards hiring outsourced personnel, the conclusion is that the large Brazilian companies are not yet prepared to manage personnel with multiple contracts.
\end{abstract}

PALAVRAS-CHAVE Terceirização, gestão de terceiros, força de trabalho flexível, gestão de pessoas, organização flexível.

KEY WORDS Outsourcing, managing outsourcing people, flexible workforce, people management, flexible organization. 


\section{INTRODUÇÃO}

Desde os anos 1980 nos países desenvolvidos e desde os anos 1990 no Brasil a literatura aponta para um processo contínuo de adequação de estratégias e inovações organizacionais de um significativo número de grandes empresas. Esse fenômeno acabou provocando transformações nas estruturas empresariais, na busca de um arranjo organizacional que possibilitasse maiores e mel hores resultados. Os modelos de gestão tradicionais que marcaram o período fordista caracterizados pelo controle, pela central ização e pela hierarquização - passaram a ser substituídos por modelos mais flexíveis, mais horizontalizados. Como ressaltam Galbraith e Lawler (1995), vários novos arranjos organizacionais nessa linha se mostraram mais adequados às novas exigências de um mercado competitivo que demanda constante redução nos custos, qualidade, velocidade de produção e atendimento ao cliente.

O novo modelo de organização flexível implicou a desval orização de muitas características da grande organização fordista, tida com rígida, valorizando a capacidade de adaptação rápida às contínuas transformações de mercado. As empresas têm aumentado sua capacidade de inovação, adotan do formas mais flexíveis de gestão (Galbraith, 1995; Nadler e Tushman, 2000; Dellagnelo e Silva, 2000; Baldi, 2002). Adicionalmente, após um passado de atuação isolada, em que cada empresa tinha fronteiras nítidas, novas combinações de operações passam a ser buscadas em forma de alianças ou joint ventures, visando solucionar deficiências de conhecimentos, de capital e de acesso a novos mercados (Nadler, Gerstein e Shaw, 1993).

As estruturas empresariais em rede, representadas em grande parte pelo aprofundamento e maior abrangência dos processos de terceirização, se transformam numa tendência, como salientam autores como Lipnack e Stamps (1994). Os negócios passam em parte a ser feitos por um conjunto de empresas, somam-se recursos, fazem-se intercâmbios técnicos e complementares, sem que as empresas percam sua independência. Galbraith (1995) e Tenório (2000) destacam o impacto dos novos arranjos organizacionais nos hábitos das pessoas, nos modelos de gestão e na organização da força de trabalho, encorajando formas mais cooperativas, flexíveis e participativas. Nesse modelo, ganhou força a flexibilização da remuneração (via recompensa por resultados), a flexibilização da jornada (via horários flexíveis) e, em especial no que tange ao objeto de estudo deste artigo, a flexibilização do contrato de trabal ho (sobretudo via terceirização).

A flexibilização do contrato de trabalho é simbolizada por Handy (1992) na sua conhecida figura do trevo, cujas folhas representam três grupos distintos de profissionais: o núcleo de trabal hadores efetivos da empresa, os trabal hadores contratados que atuam fora da empresa e os trabalhadores temporários ou em regime parcial. Embora, de forma embrionária, essa flexibilização da força de trabalho sempre tenha existido, hoje a escala e o grau de complexidade são muito maiores. Essa flexibilização denota a tendência de redução do núcleo de trabalhadores diretamente contratados em tempo integral pelas empresas, os core workers, com melhores salários e condições de trabaIho, ao mesmo tempo em que ocorre a ampliação do número de temporários, autônomos e prestadores de serviço, terceirizados, trabalhando em regime integral ou parcial, via de regra com menor remuneração e piores condições de trabalho (Pastore, 1994; Mattoso, 1995; Pettinger, 1998).

Se, por um lado, as empresas flexibilizaram seus vínculos de trabal ho para se tornarem mais competitivas, essa flexibilização, para a maioria dos trabalhadores, representou maior insegurança no emprego e a perda de direitos trabal histas com efeitos mais graves. Exemplos disso são as tensões resultantes das polarizações e 0 aumento da exclusão social, particularmente em países menos desenvolvidos, como o Brasil. Esse fenômeno é discutido na literatura da área organizacional por autores como Gorz (1995), Offe (1997), Dedecca (1997) e Antunes (2001), cujo referencial teórico baseia-se na sociologia e na economia do trabal ho.

Dentro da complexidade e abrangência dessa temática, o presente artigo pretende contribuir de forma inovadora ao evidenciar os efeitos - ainda pouco discutidos na literatura - da flexibilização do contrato de trabalho sobre a gestão das grandes empresas brasileiras, focando a visão dos executivos sobre os desafios da complexa gestão de terceirizados.

Para isso, o artigo é dividido em quatro partes. A primeira apresenta uma síntese dos estudos que se dedicaram ao desafio de gerir terceirizados, ângulo desta temática ainda pouco contemplado na literatura. A segunda parte relaciona os procedimentos metodológicos da pesquisa quantitativa realizada com a significativa amostra de 513 dirigentes de 179 dentre as 500 maiores empresas em operação no Brasil, abrangendo todos os setores das principais atividades econômicas do país. A terceira parte analisa os resul- 
tados da pesquisa quanto à evolução da gestão de pessoas em múltiplos vínculos contratuais, nos últimos três anos. A quarta parte são as considerações finais, que apontam para o despreparo das empresas na gestão dos terceirizados.

\section{GESTÃO DOS MÚLTIPLOS VÍNCULOS CONTRATUAIS}

Para maior compreensão da complexidade da gestão de pessoas com múltiplos vínculos contratuais - que doravante denominaremos genericamente terceiriza- dos - , os variados tipos de vínculos encontrados na literatura foram aqui agrupados em dois quadros de referência, apresentados a seguir. Enquanto o Quadro 1 se baseia nos fatores jornada e tempo de determinação do contrato de trabalho, o Quadro 2 funda-se no tipo de vínculo formal do contrato, ou seja, contrato direto (contratado pela própria empresa) ou indireto (contratado por terceiros).

Nadler, Gerstein e Shaw (1993), bem como Drucker (2002), salientam que os parâmetros tradicionais e as práticas de gestão de pessoas, projetados para trabalhadores com dedicação integral e exclusiva à empresa, ou seja, para os core workers, são questionados quando

Quadro 1 - Tipos de vínculos segundo a jornada e o tempo de duração do contrato de trabalho.

\begin{tabular}{|c|c|}
\hline TIPOS DE VÍNCULOS & CONCEITUAÇÃO \\
\hline $\begin{array}{l}\text { Trabalho por tempo } \\
\text { indeterminado }\end{array}$ & $\begin{array}{l}\text { Trabalho contratado sem tempo determinado para encerrar, mais comum em trabalhadores em tempo integral, } \\
\text { podendo abranger profissionais contratados direta ou indiretamente pela empresa (Mattoso, 1995). }\end{array}$ \\
\hline $\begin{array}{l}\text { Trabalho por tempo } \\
\text { determinado }\end{array}$ & $\begin{array}{l}\text { Trabalho contratado com período determinado para encerrar, com prazo de início e fim das atividades, } \\
\text { podendo abranger profissionais contratados direta ou indiretamente pela empresa (Silva e Antunes, 2002). }\end{array}$ \\
\hline $\begin{array}{l}\text { Contrato por horas } \\
\text { anuais }\end{array}$ & $\begin{array}{l}\text { Contrato que estabelece, entre } 0 \text { indivíduo e a organização, o número de horas trabalhadas (Murphi, } \\
\text { 1996). }\end{array}$ \\
\hline Trabalho integral & $\begin{array}{l}\text { Trabalho contratado por tempo em geral indeterminado, na maioria das vezes com todas as garantias } \\
\text { legais, melhores benefícios e condições de trabalho, inclusive salários superiores (Mattoso, 1995). }\end{array}$ \\
\hline Trabalho parcial & $\begin{array}{l}\text { Trabalho contratado por tempo determinado ou indeterminado, com menor carga horária do que o exigido } \\
\text { em turno integral, muitas vezes com piores condições de salário e trabalho que os de tempo integral } \\
\text { (Mattoso, 1995; Murphi, 1996). }\end{array}$ \\
\hline $\begin{array}{l}\text { Horário flexível } \\
\text { (Flexitime) }\end{array}$ & $\begin{array}{l}\text { Período compulsório por dia ou por determinados dias, permitindo que os empregados escolham o horário } \\
\text { mais adequado, em que são mais produtivos (Robbins, 2002). Autores como Pettinger (1998) classificam } \\
\text { de hours to suit situação análoga, quando as demandas do trabalho são conciliadas com a preferência de } \\
\text { tempo dos empregados, mais livremente. }\end{array}$ \\
\hline $\begin{array}{l}\text { Trabalho por turno } \\
\text { (Shiftworking) }\end{array}$ & $\begin{array}{l}\text { Situação em que o trabalhador ou grupo de trabalhadores, tendo completado uma jornada normal de } \\
\text { trabalho, é substituído por outro(s) trabalhador(es), cobrindo todo o período de } 24 \text { horas (Pettinger, 1998). }\end{array}$ \\
\hline Continental shifts & $\begin{array}{l}\text { Trabalho realizado em determinados padrões de dias preestabelecidos, como quatro dias de trabalho e } 1 \\
\text { de folga, ou três dias e } 2 \text { de folga (Pettinger, 1998; Robbins, 2002). Pode ser complementar ao shiftworking. }\end{array}$ \\
\hline Twilight shifts & Trabalho realizado entre 17:30h e 22:30h, propiciando conciliar interesses pessoais (Pettinger, 1998). \\
\hline Trabalho condensado & $\begin{array}{l}\text { Trabalho mais comprimido, em número menor de dias por semana - exemplo: } 10 \text { horas/ dia por quatro } \\
\text { dias, no lugar de } 8 \text { horas/ dia por cinco dias (Robbins, 2002). }\end{array}$ \\
\hline
\end{tabular}


aplicados à gestão de terceirizados, sem que existam respostas maduras consistentes. No cenário empresarial brasileiro a situação não é diferente - enfatiza Gonçalves (1998), para quem existe uma desorientação general izada que atinge até os principais executivos.

A partir da adoção de diferentes tipos de vínculos de trabal ho, o gestor passa a exercer vários graus de supervisão direta e indireta no âmbito da empresa, lidando com trabalhadores com contratos muito diferenciados. Um claro paradoxo está colocado. Por um lado, aspectos como identidade e comprometimento com a empresa e com o trabalho, integração e cooperação entre core w orkers e terceirizados, bem como o sentimento de pertencer à equipe e de participar no processo de aprendizagem organizacional são relacionados por autores como M ohrman e Lawler (1995), Petinger (1998) e Sarsur et al. (2002), e exigem maior compreensão e adequada preparação da empresa. Sem isso se torna difícil integrar os diferentes tipos de vínculos contratuais. Por outro lado, como trabalhar identidade e comprometimento com terceirizados que muitas vezes têm vários níveis de supervisão a reportar, além de terem um sistema de recompensas muito pior do que os core workers? 0 discurso do "pertencimento" soa paradoxal, quando os terceirizados são tratados pelas empresas de forma tão diversa da dedicada aos core workers.

Considerando que o universo de terceirizados já ultrapassa o número de core workers em grande parte das maiores empresas brasileiras, essa dimensão da gestão não pode mais ficar em segundo plano. A escassa literatura voltada à gestão dos terceirizados reflete essa lacuna.

Quadro 2 - Tipos de vínculos segundo o contrato de trabalho.

\section{TIPOS DE VÍNCULOS}

Core workers

Terceirizados e

quarteirizados

Subcontratados

Contratados

autônomos

Compartilhamento de tarefas

Teletrabalhador

\section{CONCEITUAÇÃO}

Empregados contratados por tempo indeterminado, em geral com as garantias legais, melhores benefícios, condições de trabalho e salários (Mattoso, 1995).

Empregados de outras empresas que trabalham para a empresa central, ou são subcontratados pela empresa terceirizada, portadores de contratos mais ou menos formalizados - tempo integral, parcial ou flexivel - por tempo indeterminado ou determinado. Contratos mais informais de trabalho, situações mais precárias quanto às condições de trabalho, salários e benefícios (Salerno, 1995; Silva e Almeida, 1997).

Terceirizados que atuam na empresa-central em regime integral, parcial ou flexivel, sob a supervisão direta do gestor desta empresa central, que define todos os termos do contrato individual (Mattoso, 1995).

Prestadores de serviços contratados como autônomos, free-lancers, consultores, mantendo uma relação individualizada com a empresa. Podem variar desde apoio administrativo até especialistas utilizados para aumentar a performance organizacional, não sendo substitutos para expertises regulares, pois atuam mais pontualmente (Handy, 1992).

Divisão de um determinado posto de trabalho entre duas ou mais pessoas (Pettinger, 1998; Robbins, 2002).

Segundo Mello (1999), Hanashiro e Dias (2002) e Robbins (2002), existem diversas formas de teletrabalho, seja o empregado da própria empresa, autônomo ou dono de uma microempresa, cujo trabalho pode ser em tempo integral, parcial ou flexível, nas seguintes condições:

- home-office - em tempo parcial ou integral, como empregado, autônomo, free-lancer, seja trabalhando distante do local de trabalho ou em casa, para a empresa ou para vários clientes;

- pendular - alguns dias na residência e outros na sede da empresa;

- no escritório (de várias empresas ou da própria empresa) - que atendem empregados que moram nas proximidades;

- em sistema de hotelagem - trabalhando em local a ser utilizado esporadicamente. 
De um lado, estão os autores que fazem uma crítica contundente à terceirização sem, no entanto, proporem alternativa que não seja a de abandonar todo e qualquer processo de flexibilização da força de trabaIho. Essa corrente é inspirada na sociologia do trabaIho, nos trabalhos de Gorz (1995), Offe (1997) e Antunes (2001), que centram sua contribuição na denúncia do trabal ho mais precário dos terceirizados.

Do outro lado, estão os autores que, sem negar a pior condição dos terceirizados, assumem a terceirização como fator inerente à nova lógica da configuração organizacional, compondo uma corrente muito menor que a supracitada. No entanto, esses autores, como Galbraith (1995) e Pettinger (1998), ficam circunscritos a uma visão algo idealizada e prescritiva de quais deveriam ser as práticas de gestão de pessoas voltadas para os terceirizados. Pettinger, por exemplo, enfatiza a necessidade de inserir a gestão dos terceirizados no contexto estratégico da empresa, chamando a aten ção para al guns fatores tidos como primordiais, a saber: comprometimento de longo prazo por parte da alta administração em propiciar o ambiente e as condições necessárias à atuação dos terceirizados; visão de longo prazo sobre os resultados desejados a partir da contratação de terceirizados; investimento em tecnologia, treinamento e desenvolvimento dos terceirizados; e investimento em métodos, procedimentos e práticas adequadas ao trabalho desses profissionais.

Procurando contribuir para a superação dessa lacuna, o presente artigo - ao mesmo tempo em que assume a terceirização como inerente e necessária ao novo ambiente organizacional - examina a evolução das práticas de gestão de pessoas em relação aos terceirizados, abandonando a visão idealizada e prescritiva do que deveria ser a ação empresarial. Adicionalmente, este artigo assume a necessi dade da revisão do escopo e das oportunidades geradas pel os programas de terceirização, diante do consenso da literatura de que as condi ções de trabal ho dos terceirizados são em geral piores do que as dos core workers, e dos indícios revel ados em pesquisas sobre a disfuncionalidade da gestão de pessoas em tais programas.

Rodrigues e Cunha (2000), discutindo os desafios da gestão de pessoas em geral, enfatizam que os mecanismos de gestão devem ser geridos por meio de coordenação e confiança. Tenório (2000) chama a atenção para alguns pontos de interação entre o trabalhador e a organização nesse ambiente de maior flexibilidade: maior au tonomia e partici pação nos processos decisó- rios; equipe e conjunto de tarefas substituindo o trabalho individual; políticas salariais voltadas para 0 desempenho da equipe. Segundo Sink e Tuttle (1993), em seu trabal ho com organizações consideradas excelentes, os programas de remuneração variável relacionados ao cumprimento de metas empresariais são uma das práticas de gestão primordiais para a adesão dos trabal hadores aos objetivos empresais.

Diante desses novos parâmetros e tendências da gestão de pessoas, e considerando que os tercei rizados são freqüentemente em maior número que os core workers, para os quais estas práticas têm sido levadas a cabo, Pettinger (1998) reforça alguns pontos considerados fundamentais para a gestão dos terceirizados, além da busca pelo comprometimento por meio de contratos de trabal ho claros; responsabilidade e autonomia pelos recursos utilizados e pela organização do trabalho; e, feedback regular sobre a performance.

No entanto, al gumas indagações são suscitadas. Primeiro, mesmo dentro do atual quadro de deificação do gestor, de exigências mais complexas colocadas para as lideranças empresariais, não seria exigir demais que essas lideranças consigam estabelecer a confiança e o comprometimento dos terceirizados com sistemas de compensação tão pouco satisfatórios para eles? Segundo, o que dizer da autonomia e participação nos processos decisórios, objetivos já bastante desafiadores em se tratando de core workers? Terceiro, como estabelecer políticas integradoras de remuneração de resultados se a grande maioria da força de trabal ho terceirizada está fora desses programas, como mostrou a pesquisa?

M owhrman e Lawler (1995) chamam a atenção para a necessidade da adequação das políticas e práticas de gestão de pessoas, o que, segundo Gonçal ves (1998), ainda é prematuro nas empresas brasileiras. Diante da carência de condições que apóiem a gestão dos múltiplos vínculos contratuais, Gonçal ves considera que os principais executivos começam a duvidar de sua competência para lidar com os novos desafios. Reforçando essa constatação, como já mencionado, Drucker (2002) afirma que os sistemas e práticas de gestão de pessoas em vigor nas empresas, em geral, ainda estão muito estruturados com foco apenas nos core workers, passando ao largo da maioria da força de trabalho, atualmente constituída de tercei rizados.

Estudos realizados por Sarsur et al. (2002), que pesquisaram 349 empresas de grande porte no Brasil, bem como pesquisas desenvolvidas por Costa (1994), Faria (1994) e Silva e Almeida (1997), revelam dificuldade de integração entre as culturas das empresas 
centrais e terceirizadas com vários desafios para os gestores. Os principais desafios são: a) contar com uma equipe qualificada de terceiros, autônomos e demais prestadores de serviço; b) reter os trabalhadores que apresentam melhor desempenho; c) gerir pessoas sobre as quais não se tem interferência direta na movimentação, desenvolvimento e carreira; d) obter conformidade do produto ou serviço aos padrões contratados; e) obter comprometimento dos terceirizados; f) estabelecer relacionamento de confiança e relação de parceria entre a empresa central e os terceirizados; g) otimizar tempo, energia e recursos na gestão da complexa rede de fornecedores e serviços terceirizados, com aumento dos custos de transação; h) lidar com o choque cultural entre os tercei ros e os core workers; i) implantar processos que garantam a sel eção mais adequada do terceiro; j) acompanhar o nível de satisfação dos clientes com o trabal ho dos terceiros.

Portanto, o gestor é desafiado a lidar com questões conflituosoas e até paradoxais, concordando com Caldas et al. (2001). O paradoxo está no fato de que a empresa exige adesão indiferenciada dos trabalhadores sem cumprir a parte que Ihe cabe nesse pacto, sem propiciar o ambiente organizacional e recursos favoráveis e adequados ao trabalho dos profissionais nos diferentes tipos de vínculos contratuais. 0 aumento das condições de vulnerabilidade dos trabal hadores nos diferentes tipos de contrato cria uma cultura de insegurança no trabalho e reforça o sentimento de não pertencimento. Como salientam Rodrigues e Cunha (2000) e N ovelli (2002), o reduzido investimento em capacitação e desenvolvimento, a ausência de transparência e clareza nas expectativas de desempenho e a falta de acompanhamento e orientação ao trabalhador reforçam essa observação. Dessa forma, o grande desafio está em desenvolver nas lideranças gerenciais a competência para definir com clareza o porquê, para quê, onde e como gerir os terceirizados; assegurar que os serviços prestados pel os terceiros sejam adequados e efetivos; e coordenar os múltiplos vínculos contratuais, de modo contínuo (Handy, 1992; Ulrich, 1997; U seem e Harder, 2000; N adler e Tushman, 2000).

\section{PROCEDIMENTOS METODOLÓGICOS}

O objetivo geral da pesquisa foi identificar se as práticas de gestão de pessoas são adequadas à fl exibilização dos vínculos de trabalho, na perspectiva dos primeiros níveis de gestores empresariais de grande porte no
Brasil. Foram consideradas as diferenças entre a gestão de empregados da própria empresa, trabalhando em tempo integral, com carteira assinada - os core workers - e a gestão dos profissionais terceirizados, aqui abrangendo os autônomos e demais prestadores de serviço.

0 estudo em questão é caracterizado como descritivo, uma vez que se propôs, em conformidade com a caracterização de levantamentos descritivos, determinar a incidência e a distribuição das características e das opiniões de determinada população e o estabelecimento de relações entre variáveis, obtendo características presumivelmente representativas dessas opiniões (Marconi e Lakatos, 1990; Malhotra, 2001).

A abordagem de pesquisa utilizada foi a quantitativa. 0 método utilizado - survey com gestores de empresas de grande porte - justificou-se pela grande extensão geográfica pesquisada, o grande número de empresas e respondentes e, ainda, pela intenção de obter dados que permitissem análises estatísticas. 0 questionário utilizou uma escala de tipo Likert para as questões relacionadas à gestão dos múltiplos vínculos de trabal ho, o que possibilitou, como ressal tam M arconi e Lakatos (1990), a obtenção de uma graduação quantificada das proposições distribuídas entre os pesquisados, podendo ser calculado um índice de cada um deles.

0 projeto de pesquisa se baseou em um questionário sobre gestão de terceirizados. Considerando-se que pesquisas quantitativas não permitem maior verticalização de algumas informações, ressalta-se que não se pretende esgotar o tema, mas sim contribuir para a discussão sobre a gestão dos múltiplos vínculos de trabal ho no contexto das grandes empresas que operam no Brasil, tendo como referência a perspectiva de seus gestores do mais al to nível.

0 questionário foi enviado eletronicamente a $2 \mathrm{mil}$ presidentes, diretores e altos executivos de 439 empresas de grande porte, dentro do universo das 500 maiores empresas (Exame: M el hores e Maiores, 2003). Foram respondidos 680 questionários; porém, destes foram utilizados, para efeito da pesquisa, 513 questionários de 179 dessas empresas, por estarem completamente preenchidos. 0 instrumento de pesquisa, cujo objetivo foi compreender a percepção dos gestores frente aos desafios da flexibilização dos vínculos de trabaIho, conteve 35 questões fechadas, 28 das quais destinaram-se a comparar as diferenças do tratamento dado aos core workers em relação aos terceirizados. Foram utilizadas duas colunas, uma para o momento atual e 
a outra para três anos atrás, o que permitiu uma análise da evolução, nos últimos três anos, da gestão dos profissionais nos múltiplos vínculos de trabalho. Uma última questão fechada teve o objetivo de identificar a ten dência, na perspectiva dos gestores, da evolução na contratação de terceirizados.

0 pré-teste para verificação da adequação do questionário contou com a participação de 10 gestores que, além de responderem ao questionário por via eletrônica, foram entrevistados para opinarem a respeito da clareza, da facilidade de preenchimento, do entendimento do conteúdo analisado, da adequação das perguntas quanto ao conteúdo, ao número e à complexidade das questões.

A amostra de gestores utilizada no estudo pode ser definida como aleatória simples, uma vez que contemplou número bastante significativo de executivos das 500 maiores empresas do Brasil. Tal amostra é composta pelos primeiros níveis da gestão, sendo representativo o percentual de $58,1 \%$ de dirigentes - presidentes, diretores ou gerentes estratégicos - de 179 das maiores empresas do Brasil. A grande maioria dos pesquisados possui mais de cinco anos de empresa ( $82 \%$ ), sendo que, destes, $48 \%$ com mais de 15 anos. Do total, 70\% encontram-se na indústria, seguidos dos setores de serviço e comércio. 0 tipo de controle de capital é predominantemente privado (94\%), sendo que $56 \%$ se encontram em empresas multinacionais, cujas práticas de gestão de pessoas são altamente influenciadas ou mesmo ditadas pelas práticas adotadas nas matrizes. Dos 513 gestores pesquisados, 83\% trabal ham em empresas que apresentam faturamento superior a 500 milhões de reais/ano. Do total das empresas, $78 \%$ possuem mais de mil empregados e $42 \%$ mais de mil terceirizados.

As respostas dos questionários foram automaticamente tabuladas por meio de sistema desenvolvido especialmente para tal fim. Para a análise dados, foi utilizado 0 Statistic Package for Social Science (SPSS). Em relação às questões em escala numérica, ou seja, para as variáveis quantitativas, foi utilizada a média. Todos os intervalos de confiança utilizados foram de $95 \%$. Conforme Triola (1999), os intervalos de confiança estão associados a um grau de confiança, que é uma medida de certeza de que o intervalo contém o verdadeiro valor do parâmetro populacional. Assim, pode-se deduzir que há $95 \%$ de confiança de que o intervalo produzido contenha o verdadeiro valor da média populacional, ou seja, que reflita a média da opinião de todos os gerentes das 500 maiores empresas do Brasil.
Para verificar a existência de uma diferença significativa entre as médias dos aspectos relacionados com empregados e dos aspectos relacionados aos tercei rizados, foram realizados testes de hipótese (teste t para amostras emparelhadas). 0 mesmo processo foi utilizado para verificar a existência de diferença entre a situação atual e a situação há três anos. As hipóteses relacionadas ao teste são:

- $H_{0}$ : não existe diferença significativa entre as médias; - $\mathrm{H}_{1}$ : existe diferença significativa entre as médias.

Como critério de decisão para rejeição ou não de uma hipótese foi utilizado o valor-p. N as situações em que o valor-p é inferior a 5\% $(0,05)$, rejeitou-se a hipótese $\mathrm{H}_{0^{\prime}}$ ou seja, há evidências de que há diferença significativa entre as médias comparadas. Para verificação da existência de diferença na evolução entre os aspectos da gestão direcionados aos core w orkers e aos terceirizados, foram criadas variáveis de apoio contendo a diferença da nota de cada respondente ao item em questão, tanto para core workers quanto para terceirizados. A pós a criação dessas variáveis para o período anual e para o período de três anos, foi realizado outro teste de hipótese para amostras emparelhadas. Com esse procedimento, foi possível verificar a existência ou não de diferença significativa na evolução do tratamento concedido aos core workers e aos terceirizados.

\section{ANÁLISE DOS RESULTADOS}

\section{Comparando core workers e terceirizados}

$\mathrm{Em}$ todos os aspectos da gestão de pessoas pesquisados verificou-se que tanto atual mente quanto há três anos os terceirizados revelaram médias significativamente inferiores às dos core workers (veja a Tabela 1). A análise dos aspectos da gestão relativos aos core workers, no contexto atual, revela que, na opinião dos gestores, praticamente todos os aspectos pesquisados encontram-se presentes em nível satisfatório, ou seja, na faixa entre 5,0 e 6,0. Apresenta média inferior $(4,5)$ somente 0 aspecto relativo ao compartilhamento da aprendizagem dos core workers com os demais profissionais terceirizados. Essa menor incidência denota a dificuldade ainda encontrada pelas empresas em criar mecanismos que propiciem a gestão do conhecimento organizacional, na contramão do proposto por UIrich (1997), que destaca a importância do investimento em sistemas, processos e ferramentas que estimulem 0 
envolvimento dos trabal hadores na geração e manutenção de aprendizado contínuo como um dos aspectos-chave para que as empresas sejam capazes de atender às exigências do mercado.

As maiores médias obtidas referem-se à recompensa monetária aos core workers pela consecução das metas $(5,96)$ e ao acompanhamento do seu desempenho e resultados obtidos $(6,0)$ (veja a Tabela 1). Esse resultado refl ete 0 aumento das práticas relativas à remuneração por resultados, tendência explicitada por muitos autores, como Sink e Tuttle (1993). Embora ainda não tenham atingido patamares de excelência, as empresas pesquisadas estão, conforme ressalta Ulrich (1997), criando condições para que o gestor consiga engajar os core workers no al cance dos objetivos contratados, acompanhando seu desempenho e facilitando seu desenvolvimento.

Se há essas evidências positivas no contexto atual em relação à gestão dos core workers indicam uma posição satisfatória dentre as empresas consideradas referência no Brasil, em contraste é significativa a discrepância encontrada nos mesmos aspectos da gestão, no que tange aos terceirizados. Essa discrepância nos remete a Drucker (2002), quando afirma que 0 atual quadro de múltiplos vínculos contratuais somente proporcionará maior flexibilidade e rapidez de resposta às necessidades do mercado se a interligação entre seus vários componentes for assegurada. Entretanto, essa interligação ainda está longe de ser alcançada nas empresas pesquisadas, segundo a opinião dos dirigentes empresariais entrevistados. Comparando as médias recebidas pelos terceirizados com as médias dos core workers, praticamente todas se encontram significativamente abaixo (veja a Tabela 1).

A maioria dos aspectos da gestão dos terceirizados obteve médias entre 4 e 5 (veja a Tabela 1). A gestão denota estar mais fragilizada no que tange à extensão das práticas de treinamento adotadas para os core workers $(3,96)$, autonomia para realização do trabaIho $(3,45)$ e desenvolvimento pelos terceirizados de atividades consideradas estratégicas nas empresas $(3,25)$. Apresentam as menores médias os aspectos relativos à recompensa monetária aos empregados por atingirem as metas $(2,96)$, exercício de posições de liderança pelos terceirizados $(2,42)$, participação nas decisões estratégicas da empresa $(2,60)$, e extensão das práticas de remuneração e benefícios adotadas para os core workers $(2,43)$.

De todos os aspectos pesquisados em relação aos terceirizados, foi encontrada média superior a 5 so- mente no acompanhamento pelo gestor do desempenho e dos resultados obtidos (5.16), no poder dos gestores em escolher com quem trabalhar $(5,37)$, e ainda na obediência aos padrões, normas e procedimentos definidos pela empresa $(5,83)$, que é a maior média encontrada atualmente dentre todos os aspectos da gestão de terceirizados.

Essas evidências se coadunam com as suposições de Nadler, Gerstein e Shaw (1993) e Drucker (2002) quando afirmam ser ainda precária a gestão de pessoas num ambiente flexível. O s dados da pesquisa sugerem que as grandes empresas no Brasil estão ainda muito distantes da equalização das práticas e políticas de gestão de pessoas entre core workers e terceirizados. Uma análise da evolução desses aspectos nos últimos três anos propiciará uma melhor compreensão desse cenário, que será tratado a seguir.

\section{Evolução dos aspectos de gestão de pessoas}

Há três anos as médias eram significativamente inferiores às atuais, o que sugere evolução nas políticas e práticas de gestão de pessoas, nas empresas brasileiras de grande porte, tanto para core workers quanto para terceirizados. Em relação aos core workers, na opinião de seus dirigentes e gestores, quase a totalidade dos aspectos pesquisados obtiveram média entre 4 e 5 , enquanto no cenário atual as médias estiveram em sua maioria superiores a 5 (veja a Tabela 1). As exceções encontradas naquela época repetem as evidências atuais, em que a menor média se refere ao compartilhamento da aprendizagem dos empregados com os trabal hadores nos demais vínculos $(3,73)$, bem como as maiores médias, superiores a 5 , referem-se ao poder dos gestores em escolher os core workers com quem trabal har e à prática de recompensá-los monetariamente por atingirem as metas.

Em relação à evolução dos aspectos da gestão dos terceirizados a maioria obteve média entre 3 e 4, enquanto no contexto atual a maioria esteve entre 4 e 5. Novamente as exceções observadas naquele período repetem a realidade atual, em que as menores médias encontradas foram a extensão das práticas de treinamento adotadas com os core workers $(3,13)$, a autonomia dos terceirizados $(2,83)$, o desenvolvimento pelos terceirizados de atividades consideradas estratégicas nas empresas $(2,67)$, a recompensa monetária dos terceirizados por atingirem as metas $(2,39)$, o exercício de posições de liderança pelos terceirizados $(2,20)$, e a extensão das práticas de remuneração e benefícios adotadas para os core workers $(2,09)$. Os destaques 
Tabela 1 - Evolução da gestão de core workers e terceirizados nos últimos três anos.

\begin{tabular}{|c|c|c|c|c|c|c|c|}
\hline \multirow{2}{*}{$\begin{array}{l}\text { ASPECTOS DA GESTÃO COMPARANDO } \\
\text { CORE WORKERS E TERCEIRIZADOS }\end{array}$} & \multicolumn{2}{|c|}{ MÉDIA } & \multicolumn{2}{|c|}{ DIFERENÇA ENTRE MÉDIAS } & \multicolumn{2}{|c|}{ MÉDIA E/T } & \multirow{2}{*}{ 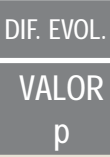 } \\
\hline & ATUAL & 3 ANOS & $\begin{array}{l}\text { ATUAL E } \\
3 \text { ANOS }\end{array}$ & $\begin{array}{c}\text { VALOR } \\
p\end{array}$ & ATUAL & 3 ANOS & \\
\hline $\begin{array}{l}\text { A1 e A2 - demonstram comprometimento com os } \\
\text { resultados da empresa. }\end{array}$ & $\begin{array}{l}\text { E. } 5,81 \\
\text { T. } 4,43\end{array}$ & $\begin{array}{l}\text { E. } 4,81 \\
\text { T. } 3,57\end{array}$ & $\begin{array}{l}\text { E. } 1,00 \\
\text { T. } 0,86\end{array}$ & $\begin{array}{l}0,000 \\
0,000\end{array}$ & $\begin{array}{r}1,41 \\
* *\end{array}$ & 1,27 & 0,007 \\
\hline $\begin{array}{l}\text { A3 e A4 - gestores negociam os objetivos, metas e } \\
\text { recursos necessários. }\end{array}$ & $\begin{array}{l}\text { E. } 5,71 \\
\text { T. } 4,54\end{array}$ & $\begin{array}{l}\text { E. } 4,60 \\
\text { T. } 3,28\end{array}$ & $\begin{array}{l}\text { E. } 1,11 \\
\text { T. } 1,13\end{array}$ & $\begin{array}{l}0,000 \\
0,000\end{array}$ & 1,17 & 1,19 & 0,809 \\
\hline $\begin{array}{l}\text { A5 e A6 - práticas de gestão estimulam } 0 \\
\text { desenvolvimento. }\end{array}$ & $\begin{array}{l}\text { E. } 5,67 \\
\text { T. } 4,26\end{array}$ & $\begin{array}{l}\text { E. } 4,76 \\
\text { T. } 3,34\end{array}$ & $\begin{array}{l}\text { E. } 0,90 \\
\text { T. } 0,92\end{array}$ & $\begin{array}{l}0,000 \\
0,000\end{array}$ & 1,41 & 1,43 & 0,703 \\
\hline $\begin{array}{l}\text { A7 e A8 - práticas de gestão estimulam a } \\
\text { cooperação. }\end{array}$ & $\begin{array}{l}\text { E. } 5,14 \\
\text { T. } 4,81\end{array}$ & $\begin{array}{l}\text { E. } 4,13 \\
\text { T. } 3,83\end{array}$ & $\begin{array}{l}\text { E. } 1,01 \\
\text { T. } 0,98\end{array}$ & $\begin{array}{l}0,000 \\
0,000\end{array}$ & 0,34 & 0,30 & 0,289 \\
\hline A9 e A10 - sentem-se com autonomia para decidir. & $\begin{array}{l}\text { E. } 5,12 \\
\text { T. } 3,45\end{array}$ & $\begin{array}{l}\text { E. } 4,21 \\
\text { T. } 2,83\end{array}$ & & $\begin{array}{l}0,000 \\
0,000\end{array}$ & $\begin{array}{l}1,67 \\
* *\end{array}$ & 1,39 & 0,000 \\
\hline $\begin{array}{l}\text { A11 e A12 - gestores negociam expectativas de } \\
\text { desempenho e resultados. }\end{array}$ & $\begin{array}{l}\text { E. } 5,77 \\
\text { T. } 4,63\end{array}$ & $\begin{array}{l}\text { E. } 4,62 \\
\text { T. } 3,51\end{array}$ & $\begin{array}{l}\text { E. } 1,15 \\
\text { T. } 1,12\end{array}$ & $\begin{array}{l}0,000 \\
0,000\end{array}$ & 1,14 & 1,11 & 0,474 \\
\hline $\begin{array}{l}\text { A13 e A14 - sabem o que fazer para atender às } \\
\text { expectativas dos gestores. }\end{array}$ & $\begin{array}{l}\text { E. } 5,70 \\
\text { T. } 4,86\end{array}$ & $\begin{array}{l}\text { E. } 4,63 \\
\text { T. } 3,79\end{array}$ & $\begin{array}{l}\text { E. } 1,06 \\
\text { T. } 1,07\end{array}$ & $\begin{array}{l}0,000 \\
0,000\end{array}$ & 0,84 & 0,84 & 0,872 \\
\hline $\begin{array}{l}\text { A15 e A16 - os gestores acompanham o } \\
\text { desempenho e os resultados. }\end{array}$ & $\begin{array}{l}\text { E. } 6,0 \\
\text { T. } 5,16\end{array}$ & $\begin{array}{l}\text { E. } 4,95 \\
\text { T. } 3,99\end{array}$ & $\begin{array}{l}\text { E. } 1,05 \\
\text { T. } 1,16\end{array}$ & $\begin{array}{l}0,000 \\
0,000\end{array}$ & $\begin{array}{l}0,85 \\
* *\end{array}$ & 0,96 & 0,004 \\
\hline $\begin{array}{l}\text { A17 e A18 - práticas de gestão favorecem as } \\
\text { relações de confiança. }\end{array}$ & $\begin{array}{l}\text { E. } 5,25 \\
\text { T. } 4,90\end{array}$ & $\begin{array}{l}\text { E. } 4,27 \\
\text { T. } 3,94\end{array}$ & $\begin{array}{l}\text { E. } 0,98 \\
\text { T. } 0,96\end{array}$ & $\begin{array}{l}0,000 \\
0,000\end{array}$ & 0,35 & 0,33 & 0,434 \\
\hline $\begin{array}{l}\text { A19 e A20 - recebem dos gestores feedback sobre } \\
\text { seu desempenho. }\end{array}$ & $\begin{array}{l}\text { E. } 5,56 \\
\text { T. } 4,64\end{array}$ & $\begin{array}{l}\text { E. } 4,40 \\
\text { T. } 3,54\end{array}$ & $\begin{array}{l}\text { E. } 1,15 \\
\text { T. } 1,10\end{array}$ & $\begin{array}{l}0,000 \\
0,000\end{array}$ & 0,92 & 0,86 & 0,191 \\
\hline $\begin{array}{l}\text { A21 e A22 - a empresa adota processos de } \\
\text { comunicação claros. }\end{array}$ & $\begin{array}{l}\text { E. } 5,55 \\
\text { T. } 4,71\end{array}$ & $\begin{array}{l}\text { E. } 4,43 \\
\text { T. } 3,46\end{array}$ & $\begin{array}{l}\text { E. } 1,12 \\
\text { T. } 1,12\end{array}$ & $\begin{array}{l}0,000 \\
0,000\end{array}$ & 0,84 & 0,84 & 0,927 \\
\hline $\begin{array}{l}\text { A23 e A24 - aprendizagem no trabalho é } \\
\text { compartilhada com os outros profissionais. }\end{array}$ & $\begin{array}{l}\text { E. } 4,75 \\
\text { T. } 4,33\end{array}$ & $\begin{array}{l}\text { E. } 3,73 \\
\text { T. } 3,40\end{array}$ & $\begin{array}{l}\text { E. } 1,02 \\
\text { T. } 0,93\end{array}$ & $\begin{array}{l}0,000 \\
0,000\end{array}$ & $\begin{array}{l}0,42 \\
* *\end{array}$ & 0,33 & 0,004 \\
\hline $\begin{array}{l}\text { A25 e A26 - os gestores têm poder de escolher } \\
\text { com quem trabalhar. }\end{array}$ & $\begin{array}{l}\text { E. } 5,76 \\
\text { T. } 5,37\end{array}$ & $\begin{array}{l}\text { E. } 5,21 \\
\text { T. } 4,86\end{array}$ & $\begin{array}{l}\text { E. } 0,55 \\
\text { T. } 0,52\end{array}$ & $\begin{array}{l}0,000 \\
0,000\end{array}$ & 0,39 & 0,35 & 0,442 \\
\hline $\begin{array}{l}\text { A27 e A28 - são recompensados monetariamente } \\
\text { pelo atingimento das metas e resultados. }\end{array}$ & $\begin{array}{l}\text { E. } 5,96 \\
\text { T. } 2,96\end{array}$ & $\begin{array}{l}\text { E. } 5,10 \\
\text { T. } 2,39\end{array}$ & $\begin{array}{l}\text { E. } 0,86 \\
\text { T. } 0,57\end{array}$ & $\begin{array}{l}0,000 \\
0,000\end{array}$ & $\begin{array}{c}3,00 \\
* *\end{array}$ & 2,71 & 0,000 \\
\hline
\end{tabular}

ASPECTOS DA GESTÃO DOS TERCEIRIZADOS

\begin{tabular}{|c|c|c|c|c|c|c|c|}
\hline A29 - práticas de remuneração e benefícios. & 2,42 & 2,09 & 0,33 & 0,000 & - & - & - \\
\hline A30 - práticas de treinamento e desenvolvimento. & 3,96 & 3,13 & 0,83 & 0,000 & - & - & - \\
\hline A31 - exercício de posições de liderança. & 2,60 & 2,20 & 0,40 & 0,000 & - & - & - \\
\hline A32 - participam de decisões estratégicas. & 2,43 & 2,02 & 0,40 & 0,000 & - & - & - \\
\hline A33 - desenvolvem atividades estratégicas. & 3,25 & 2,67 & 0,58 & 0,000 & - & - & - \\
\hline A34 - seguem padrões, normas e procedimentos. & 5,83 & 5,01 & 0,82 & 0,000 & - & - & - \\
\hline $\begin{array}{l}\text { A35 - demonstram expectativa em vir a fazer parte } \\
\text { do quadro de empregados da empresa. }\end{array}$ & 5,38 & 5,27 & 0,11 & 0,017 & - & - & - \\
\hline
\end{tabular}

Nota: E. refere-se aos core workers. T. refere-se aos profissionais terceirizados, que abrangem os autônomos e demais prestadores de serviço.

** Itens onde há diferença significativa entre as médias dos empregados e dos terceirizados no período atual em relação há três anos. 0 valor de $p$ na tabela refere-se à diferença entre 0 momento atual e há três anos. 
positivos também confirmam os encontrados atualmente, como o poder conferido aos gestores para decidir com quem trabalhar $(4,86)$ e, por fim, o acompanhamento do desempenho dos terceirizados por parte dos gestores $(3,99)$.

Quanto à adequação dos terceirizados aos padrões, normas e procedimentos, verifica-se que a média atual é maior, considerando todos os aspectos de gestão pesquisados. Isso indica uma evolução de 0,83 ponto nos últimos três anos, conforme mostrado na Tabela 1, denotando que o grande desafio apontado pelos gestores em pesquisa realizada por Sarsur et al. (2002) vem sendo enfrentado pelas empresas.

No entanto, apesar da evidente evolução de todos os aspectos da gestão de pessoas nos últimos três anos, tanto de core workers quanto de terceirizados, percebese que, em alguns aspectos fundamentais para a gestão, aumentou a distância no tratamento dado aos terceirizados. Essa constatação denota um atraso na evolução das práticas da gestão em aspectos importantes como: recompensa monetária por atingir as metas; comprometimento com os resultados; autonomia para decidir; e compartilhamento do aprendizado. 0 único destaque importante e positivo nessa evolução encontra-se no acompanhamento do desempenho tanto dos core workers quanto dos tercei rizados, nos quais a diferença caiu de 0,96 há três anos para 0,85 atualmente.

Nos últimos três anos, as diferenças entre os core workers e os tercei rizados em aspectos rel evantes como recompensa monetária por atingir as metas se agravaram, o que mostra a dificuldade das empresas em atuarem nesse contexto mais flexível. Essas evidências ajudam a entender o grande interesse, na opinião dos gestores, dos terceirizados, autônomos e demais prestadores de serviço em integrarem os quadros da empresa central (veja a Tabela 1), tendo obtido médias superiores a 5 , há três anos e atual mente. Portanto, se associarmos o aumento da desigualdade no tocante à remuneração por resultados, autonomia e comprometimento, que são os aspectos em que houve piora relativa mais significativa, o quadro pesquisado indica que as empresas têm fal hado em três dos pressupostos mais importantes da gestão contemporânea.

\section{CONSIDERAÇÕES FINAIS}

As empresas pesquisadas ainda estão longe de se revelarem preparadas para a gestão dos profissionais tercei rizados. Considerando a relevância da amostra, pode-se inferir que esse despreparo esteja generalizado nas empresas de grande porte do país.

U ma análise da evolução dos aspectos da gestão nos últimos três anos revelou o agravamento das diferenças entre core workers e tercei rizados em aspectos fundamentais, como recompensa monetária por atingir as metas, comprometimento com os resultados, autonomia para decidir e compartilhamento do aprendizado. O único destaque positivo e de importância nessa evoIução foi o relativo ao acompanhamento do desempenho pelos gestores. Essas evidências explicam o interesse dos terceirizados, na opinião dos gestores, de virem a fazer parte dos quadros da empresa central.

U ma anál ise conjunta dos aspectos relativos ao comprometimento, à cooperação, à confiança, ao compartilhamento de aprendizagem e à autonomia denota significativa distância entre core workers e tercei rizados. Essa discrepância impacta o processo de trabal ho das equipes formadas por profissionais com diversos tipos de vínculos contratuais. A dificuldade constatada pela pesquisa para o estabelecimento de confiança na relação da gestão com os terceirizados pode ser interpretada pela falta de clareza quanto à eqüidade nas condições de trabalho, às perspectivas de desenvolvimento, à remuneração e ao tratamento diverso com relação aos terceirizados.

Nos aspectos relativos à gestão do desempenho, enquanto as empresas exigem dos terceirizados a adesão aos seus objetivos, resultados e metas, fal ham em cumprir integral mente a parte que lhes cabe nesse pacto, qual seja, a contratação clara de objetivos, negociação de expectativas, acompanhamento do desempenho e feedback em relação a eles, terceirizados. Certamente, o pior tratamento concedido aos terceirizados é um dos fatores que dificultam a contratação e retenção de profissionais com maior qualificação, motivação e comprometimento.

Quanto às práticas de gestão relativas à remuneração, à comunicação, ao poder de decisão na contratação, ao treinamento e ao desenvolvimento das pessoas, também é significativa a diferença encontrada entre terceirizados e core workers. A pesquisa sugere que, mesmo nas maiores e melhores empresas do Brasil, a remuneração por metas e resultados está longe de se tornar realidade para os terceirizados. Se estes não são remunerados conforme os resultados atingidos, podese depreender que o terceirizado encontra dificuldade em sentir-se "parte do time".

Por sua vez, os processos de comunicação constituem fator importante no engajamento desses profis- 
sionais, não apenas em relação aos aspectos produtivos, mas também aos aspectos psicossociais das relações de trabal ho em um ambiente mais flexível. Esses processos de comunicação se encontram ainda apenas medianamente desenvolvidos nas empresas pesquisadas, dificultando a uniformidade de entendimento dos propósitos e dos valores empresariais, a disseminação dos objetivos e das metas, e a sintonia entre os profissionais nos diversos tipos de vínculos de trabalho. A padronização do trabalho realizado pel os terceirizados se destaca como um dos poucos avanços obtidos nos últimos três anos. Esse aspecto não causa surpresa, u ma vez que cada vez mais empresas incluem em suas políticas de contratação de terceirizados a apresentação de certificações como a série ISO.

Diante dessas evidências, pode-se concluir que ainda é muito longo o caminho a ser percorrido pelo gestor da grande empresa no sentido de ser capaz de decidir que profissional manter como core worker e qual terceirizar; de estar preparado para melhor coordenar os diversos tipos de vínculos de trabalho; e de assegurar que os serviços prestados pel os terceiros sejam adequados e efetivos.

A pesquisa indicou que os executivos avaliam que a contratação de terceirizados poderá aumentar no futuro próximo, denotando que as maiores empresas que operam no Brasil ainda têm uma enorme trajetória a ser seguida. 0 que tem prevalecido é a lógica de redução de custos nos processos de contratação dos terceirizados. 0 paradoxo que se instala parece insolúvel nessa lógica que, ao mesmo tempo em que reduz diretamente os custos, aumenta enormemente os desafios para os gestores e exige das empresas novos investimentos na adequação de políticas e práticas de gestão de pessoas, al ém de aumentar os custos de transação. 0 resultado obtido pelas empresas se torna questionável, e a aparente redução de custos, discutível.

Diante de tamanho desafio e complexidade, novas investigações se fazem necessárias, ficando como sugestão para novos estudos e pesquisas as seguintes questões: até que ponto a adoção generalizada de múltiplos tipos de vínculo de trabalho vem contribuindo para a melhoria dos resultados empresariais? Até que ponto as empresas estão decidindo, de forma consciente, quais profissionais terceirizar e por quê? É recompensador, para as empresas, manter tantos e tão diferentes vínculos de trabalho, adotados tão genericamente, em escalas cada vez maiores? E até que ponto o necessário investimento na gestão compensará a esperada redução de custos mediante processos de terceirização?

\section{REFERÊNCIAS BIBLIOGRÁFICAS}

ANTUNES, R. Os sentidos do trabalho: ensaio sobre a afirmação e a negação do trabalho. São Paulo: Boitempo, 2001.

BALDI, M . N ovas formas organizacionais: a necessidade de superação das perspectivas sobre-socializadas e subsocializadas. In: ENCONTRO NACIONAL DA ASSO CIAÇÃO NACIONAL DOSPROGRAMASDE PÓS-GRADUAÇÃO E PESQUISA EM ADMINISTRAÇÃO, 26., 2002, Salvador. Anais. Salvador: AN PAD, 2002

CALDAS, M. P. et al. Handbook de estudos organizacionais: reflexões e novas direções. São Paulo: Atlas, 2001. v.1.

COSTA, M. S. Terceirização/parceria e suas implicações no âmbito jurídico-sindical. Revista de Administração de Empresas, v. 34, n. 1, p. 6-11, 1994.

DEDECCA, C. S. Racionalização econômica e heterogeneidade nas relações e nos mercados de trabal ho no capitalismo avançado. In: OLIVEIRA, C. A. B.; MATTOSO, J. E. L. (Orgs.). Crise e trabalho no Brasil: modernidade ou volta ao passado? São Paulo: Scritta, 1997. p. 55-85.

DELLAGNELO , E. L.; SILVA, C. L. M. Literatura sobre novas formas organizacionais: onde se encontram as evidências empíricas de ruptura com 0 modelo burocrático de organizações? In: ENCONTRO NACIONAL DA ASSOCIAÇÃO NACIONAL DOS PROGRAMAS DE PÓS-GRADUAÇÃO E PESQUISA EM ADMINISTRAÇÃO, 24., 2000, Florianópolis. Anais. Florianópolis: ANPAD, 2000.

DRUCKER, P. F. A administração na próxima sociedade. São Paulo: Nobel, 2002.

EXAME: Melhores e Maiores. As 500 maiores empresas do Brasil. São Paulo: Abril, 2003.

FARIA, A. Terceirização: um desafio para o movimento sindical. In: MARTINS, H. S.; RAMALHO, J. R. Terceirização: diversidade e negociação no mundo do trabalho. São Paulo: Hucitec-Cedi/N ets, 1994. p. 41-61.

GALBRAITH, J. R.; LAWLER, E. E. Organizando para competir no futuro: estratégia para gerenciar o futuro das organizações. São Paulo: Makron Books, 1995. p. 3-28.

GALBRAITH, J. R. A unidade de negócios do futuro. In: GALBRAITH, J. R.; LAW LER, E. E. Organizando para competir no futuro: estratégia para gerenciar o futuro das organizações. São Paulo: Makron Books, 1995. p. 29-48.

GONÇALVES, J. E. L. A necessidade de reinventar as empresas. Revista de Administração de Empresas, v. 38, n. 2, p. 6-17, 1998.

GORZ, A. Saindo da sociedade do trabalho assalariado. São Paulo em Perspectiva, São Paulo, v. 9, n. 3, p. 135-144, 1995.

HANASHIRO, D. M. M.; DIAS, W. F. O sistema de teletrabalho: algumas implicações de um ambiente virtual. In: ENCONTRO NACIONAL DA ASSOCIAÇÃO NACIONAL DOS PROGRAMAS DE PÓS-GRADUAÇÃO E PESQUISA EM ADMINISTRAÇÃO, 26., 2002, Salvador, Anais. Salvador: ANPAD, 2002.

HANDY, C. A era da irracionalidade. Lisboa: Cetop, 1992. 
LIPNACK, J.; STAMPS, J. Rede de informações. São Paulo: Makron Books, 1994.

MALHOTRA, N. K. Pesquisa de marketing: uma orientação aplicada. Porto Alegre: Bookman, 2001.

MARCONI, M. A.; LAKATOS, E. M. Técnicas de pesquisa: planejamento e execução de pesquisas, amostragens e técnicas de pesquisas, elaboração, análise e interpretação de dados. São Paulo: Atlas, 1990.

MATTOSO, J. A desordem do trabalho. São Paulo: Página Aberta, 1995.

MELLO, Á. Teletrabalho (telework): o trabalho em qualquer lugar e a qualquer hora. Rio de Janeiro: Qualitymark, 1999.

MOHRMAN, A. M.; LAWLER, E. E. Administração de recursos humanos: construindo uma parceria estratégica. In: GALBRAITH, J.; LAW LER, E. E. Organizando para competir no futuro: estratégia para gerenciar o futuro das organizaç̃̃es. São Paulo: Makron Books, 1995. p. 201-224.

MURPHI, E. Flexible Work. London: Prentice-Hall, 1996.

NADLER, D. A.; GERSTEIN, M. S.; SHAW, R. B. Arquitetura organizacional: a chave para a mudança empresarial. Rio de Janeiro: Campus, 1993.

NADLER, D. A.; TUSHMAN, M. L. A organização do futuro. HSM M anagement, São Paulo, n. 18, p. 58-66, jan.-fev., 2000.

NOVELLI, J. G. N. O valor do valor em recursos humanos. In: ENCONTRO NACIONAL DA ASSO CIAÇÃO NACIONAL DOS PROGRAMAS DE PÓS-GRADUAÇÃO E PESQUISA EM ADMINISTRAÇÃO, 26., 2002, Salvador. Anais. Salvador: AN PAD, 2002.

OFFE, C. Desemprego, sindicatos e inovação na política social. Ensaios FEE, Porto Alegre, v. 18, n. 1, p. 181-191, 1997.

PASTORE, J. Flexibilização dos mercados de trabalho e contratação coletiva. São Paulo: LTr, 1994.

PETTINGER, R. Managing the Flexible Workforce. London: Cassell, 1998.
ROBBINS, S. P. Comportamento organizacional. São Paulo: Prentice-Hall, 2002.

RODRIGUES, S. B.; CUNHA, M. P. N ovas perspectivas na administração de empresas: uma coletânea luso-brasileira. São Paulo: Iglu, 2000.

SALERNO, M. S. Flexibilidade e organização produtiva. In: CASTRO, N. A. (Org.). A máquina e o equilibrista: inovações na indústria automobilística brasileira. São Paulo: Paz e Terra, 1995. p. 53-83.

SARSUR, A. M. et al. Repensando as relações de trabalho: novos desafios frente aos múltiplos vínculos de trabalho. In: ENCONTRO NACIONAL DA ASSOCIAÇÃO NACIONAL DOS PROGRAMAS DE PÓS-GRADUAÇÃO E PESQUISA EM ADMINISTRAÇÃO, 26., 2002, Salvador. Anais. Salvador: AN PAD, 2002.

SILVA, L. V.; ANTUNES, E. D. Influência das relações flexíveis de trabal ho na qualidade de vida do trabalhador: a visão de seus atores sociais. In: ENCONTRO NACIONAL DA ASSO CIAÇÃO NACIONAL DOSPROGRAMAS DE PÓS-GRADUAÇÃO E PESQUISA EM ADMINISTRAÇÃO, 26., 2002, Salvador. Anais. Salvador: AN PAD, 2002.

SILVA, R. A. R.; ALMEIDA, M. C. Terceirização e quarteirização: indicativos estratégicos para implementação. In: ENCONTRO NACIONAL DA ASSOCIAÇÃO NACIONAL DOS PROGRAMAS DE PÓS-GRADUAÇÃO E PESQUISA EM ADMINISTRAÇÃO, 21., 1997, Rio das Pedras. Anais. Rio de Janeiro: ANPAD, 1997.

SINK, D. S.; TUTTLE, T. C. Planejamento e medição para a performance. Rio de Janeiro: Qualitymark, 1993.

TEN ÓRIO, F. G. Flexibilização organizacional: mito ou realidade? São Paulo: FGV, 2000.

TRIOLA, M. F. Introdução à estatística. Rio de Janeiro: LTC, 1999.

ULRICH, D. Organizando de acordo com a capacidade. In: HESSELBEIN, F.; GOLDSMITH, M.; BECKHARD, R. (Eds.). A organização do futuro: como preparar hoje as empresas de amanhã. São Paulo: Futura, 1997.

USEEM, M.; HARDER, J. Leading laterally in company outsourcing. Sloan Management Review, Cambridge, v. 41, n. 2, p. 25-36, 2000.

\section{Artigo recebido em 23.08.2004. Aprovado em 18.07.2005.}

\section{Maria Elizabeth Rezende Fernandes}

Professora da Fundação Dom Cabral. Doutoranda em Administração pela UFM G-CEPEAD.

Interesses de pesquisa nas áreas de gestão de pessoas, relações do trabalho, liderança e terceirização.

E-mail: bethf@fdc.org.br e merf@cepead.face.ufmg.br

Endereço: Av. Princesa Diana, 760, Alphaville Lagoa dos Ingleses, N ova Lima - M G, 34000-000.

\section{Antônio Moreira de Carvalho N eto}

Professor de Pós-Graduação em Administração da PUC-M inas e Fundação Dom Cabral. Doutor pela UFMG. Interesses de pesquisa nas áreas de gestão de pessoas, relações de trabal ho e responsabilidade social empresarial.

E-mail: irt@pucminas.br e antoniocarvalho@pucminas.br

Endereço: Rua Benvinda de Carvalho, 301, ap. 701, Belo Horizonte - Minas Gerais, 30330-180. 